\title{
Cardiovascular Emergency Surgery after Acute Renal Failure: A Case Report
}

\author{
Niklas F. Boeder, Oliver Dörr, Wiebke Rutsatz, Timm Bauer, Holger M. Nef \\ Department of Cardiology, University Hospital of Giessen, Giessen, Germany
}

\section{ABSTRACT}

We describe the case of a 68-year-old patient who was admitted to the trauma unit with anisocoria after pre-hospital resuscitation upon loss of consciousness. An intracranial bleeding was ruled out. The patient was admitted to the cardiology ward with the initial diagnosis of a syncope due to myocarditis, as myocardial necrosis markers were slightly elevated. The suspicion of an acute aortic dissection (AAD) was raised when the patient developed kidney failure and a progressive aortic regurgitation. He underwent emergency surgery for an acute type A AAD. Renal function recovered completely and, fortunately, the patient was discharged 10 days later.

Keywords: aortic dissection, emergency room, trauma room, communication, syncope

\section{ARTICLE HISTORY}

Received: July 17, 2018

Accepted: August 31, 2018

\section{CORRESPONDENCE}

\section{Holger M. Nef}

University of Giessen, Department of Cardiology

Klinikstrasse 33

35392 Giessen, Germany

Tel: +4964198542101

E-mail: holger.nef@innere.med.unigiessen.de

\section{BACKGROUND}

Patients with potentially life-threatening conditions or trauma are usually brought to the emergency department of the local hospital. A multidisciplinary team, typically led by an orthopedic surgeon and supported by an anesthesiologist and a neurosurgeon, diagnose and promptly initiate therapeutic steps, if necessary. We report the case of a patient who was initially misdiagnosed and therefore underwent emergency cardiovascular surgery for acute aortic dissection (AAD) with delay.

\section{CASE PRESENTATION}

A 68-year-old male patient lost consciousness beside his mother's deathbed. The surrounding relatives started cardiopulmonary resuscitation. Upon arrival of the emergency team, the patient had regained consciousness. ECG showed sinus rhythm, and vital parameters were in the normal tolerable range (heart rate $90 / \mathrm{min}$, blood pressure $140 / 90 \mathrm{mmHg}$ ). The patient was transferred to the trauma unit due to an anisocoria. Computed tomography (CT) only showed a subgaleal hemorrhage. The initial anisocoria disappeared spontaneously. A chest x-ray was performed due to left-sided chest discomfort after external compression (see Figure 1). A conspicuously large heart shadow and a widening of the mediastinum were observed, which may indicate a pericardial effusion (PE); however, the report of the radiologist noted that echocar- 


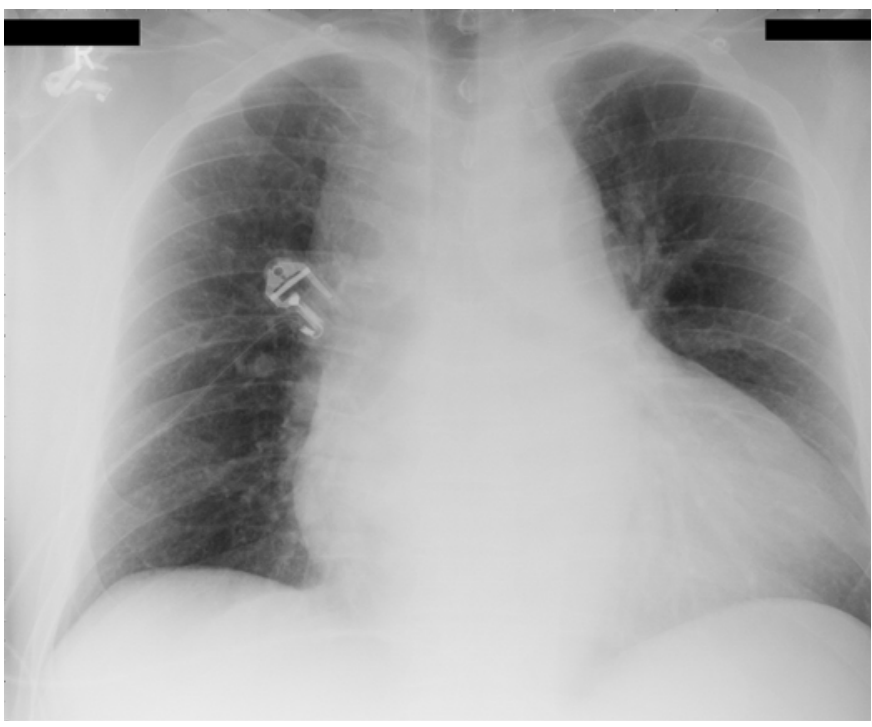

FIGURE 1. Chest $X$-ray showing a widened mediastinum and a striking large heart shadow

diography ruled out a PE beforehand. Approximately one hour later a second echocardiogram revealed an $11 \mathrm{~mm}$ wide circular effusion (see Moving Image 1 and 2). The patient was admitted to the cardiology ward with the initial diagnosis of a syncope due to myocarditis, as myocardial necrosis markers were slightly elevated. The patient developed acute kidney failure on day two. PE remained stable (see Figure 2), though the patient showed grade II aortic regurgitation (see Figure 2, Moving Image 3). The suspicion of an $\mathrm{AAD}$ was raised. CT revealed an intramural hematoma 5-6 mm away from an incomplete dissection approximately $3-4 \mathrm{~cm}$ above the aortic valve. The patient underwent emergency surgery for AAD including replacement of the aortic root with a hemiarch. Renal function recovered completely, and the patient was discharged 10 days later.

\section{DISCUSSION}

AAD usually results from a tear in the aortic intima. This forms a pressurized hematoma that typically propagates rapidly along the length of the aorta, thereby compromising branch vessels along its path or disrupting the aortic valve function. The incidence of aortic dissection is reported to be between 5 to 10 cases per million per year.,

$\mathrm{AAD}$ is a life-threatening condition. The mortality from acute type A dissection is $1 \%$ to $2 \%$ per hour during the first 24-48 h. ${ }^{3}$ Without treatment, half of the patients with acute aortic dissection die within $24 \mathrm{~h}$, and after one week, $62-91 \%$ of patients are dead. ${ }^{3,4}$ Approximately $10 \%$ to $35 \%$ of patients with acute dissection are diagnosed post-mortem. ${ }^{5,6}$

Classically, patients with AAD present with sudden, severe chest, back, or abdominal pain that is characterized as ripping or tearing in nature. ${ }^{7}$ Our patient, however, did not present the typical migratory pain. It was the transient loss of consciousness and anisocoria that led to the transfer to the trauma unit. Approximately $5 \%$ to $10 \%$ of $\mathrm{AAD}$ patients present with syncope. There are several potential pathophysiological explanations: on one hand, rupture of the proximal dissection into the pericardial space can occur, resulting in cardiac tamponade and syncope. ${ }^{8}$ On the other hand, syncope can be induced by a significant reduction of cerebral blood flow due to involvement of the carotid artery. ${ }^{9}$ Interestingly, there has been a significant decrease in the reporting of "ripping or tearing" pain over the last few decades. ${ }^{10}$

In the present case, chest $\mathrm{x}$-ray showed a widened mediastinum (see Figure 1). Chest $\mathrm{x}$-rays are read as being "normal" or may show nonspecific changes of a dilated, ectatic, or tortuous aorta in $18 \%{ }^{10,11}$ The radiologist did, furthermore, describe a conspicuously large heart shadow;

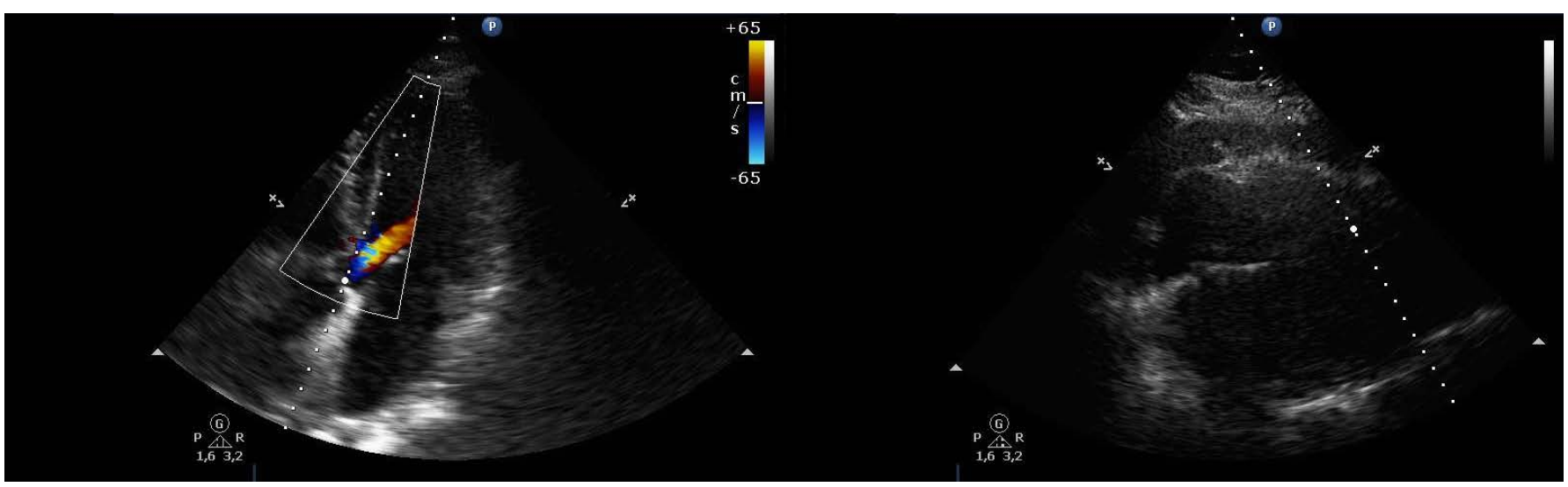

FIGURE 2. Echocardiography showing pericardial effusion and aortic regurgitation grade II 


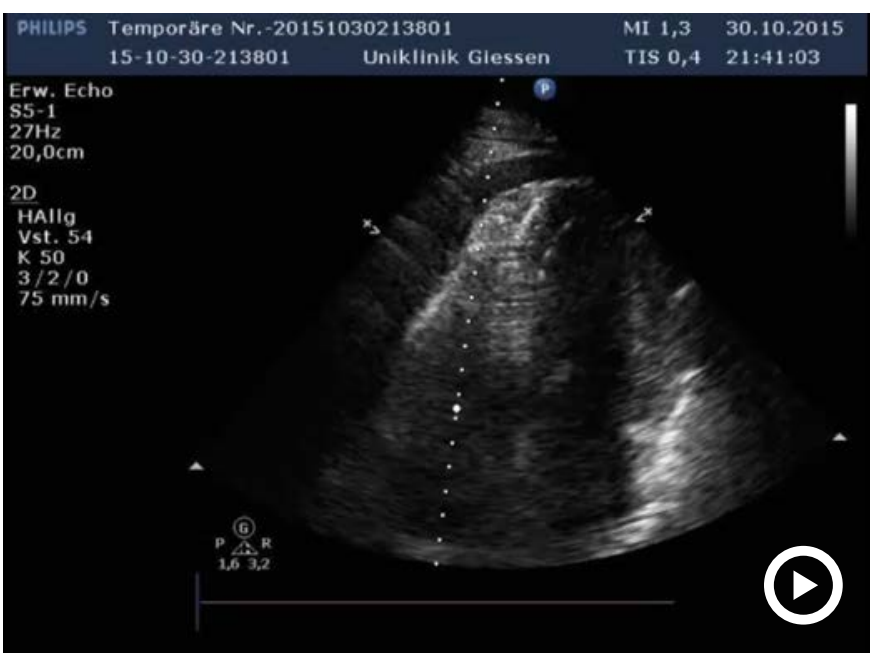

MOVING IMAGE 1. Four-chamber view with concentric pericardial effusion

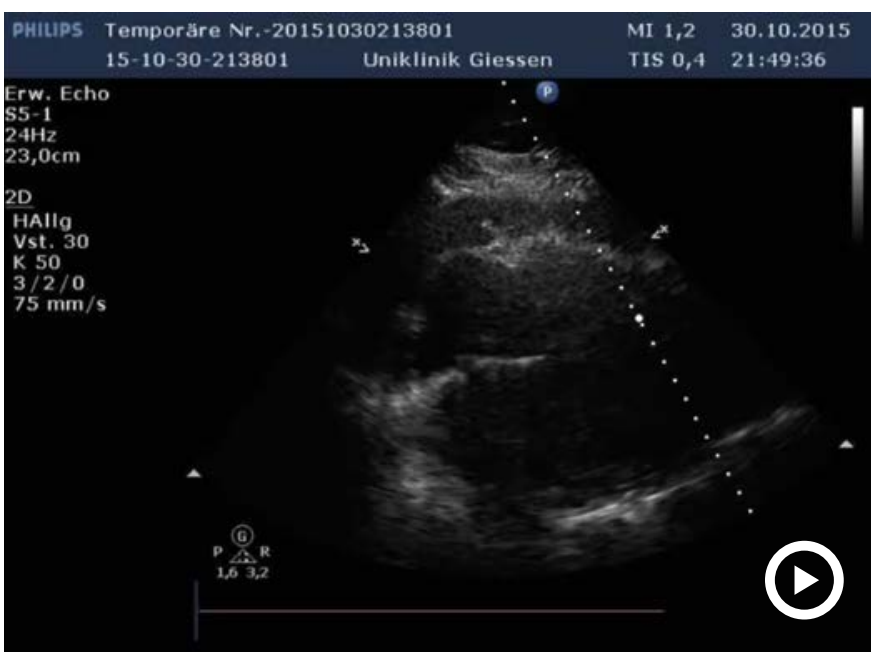

MOVING IMAGE 2. Subxiphoid view with concentric pericardial effusion

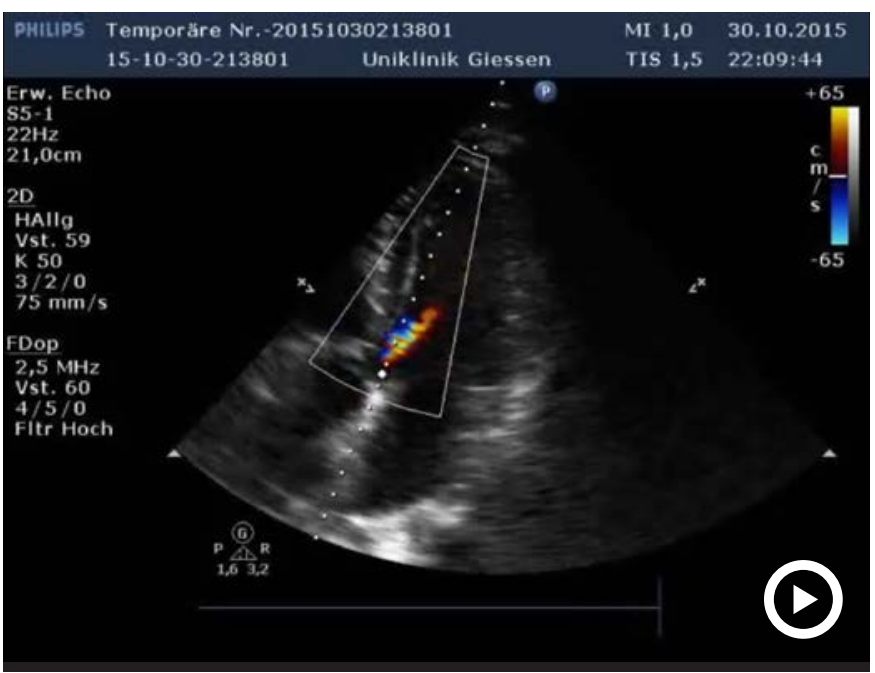

MOVING IMAGE 3. Five-chamber view with aortic regurgitation however, the importance of this finding was neglected due to an ultrasound that was reported not to have shown a PE. It should be noted that this report was not documented in written form. Another reason why the chest x-ray might not have influenced the further course of the patient's treatment at that point, might be the fact that the trauma unit typically makes use of CT to rule out life-threatening conditions. In the present case, CT was only used in the head region and showed a subgaleal hemorrhage.

The patient was reported to be normotensive and hemodynamically stable all the times. Therefore, the clinical course was uneventful until laboratory tests indicated acute kidney failure ( $\uparrow$ serum creatinine $>300 \%$ $(>3 \times)$, urine output $<0.3 \mathrm{~mL} / \mathrm{kg} / \mathrm{h}$ ), and echocardiography showed aortic regurgitation. There are three potential mechanisms for pre-renal kidney failure: first, a delayed reaction to hypotension during resuscitation; second, a progression of the dissection and involvement of the renal artery; and third, a PE..$^{12}$ As the patient required intensive antihypertensive therapy after surgery, the observed normotension upon admission has to be relativized and to be stated that renal failure most likely was due to PE. It remains unclear whether the aortic regurgitation was progressive as subsequent echocardiographies only focused on the size of the pericardial effusion.

\section{CONCLUSION}

The patient lost consciousness at his mother's deathbed. This exceptional circumstance possibly hindered the use of further CT diagnostics of the chest. As the initial echocardiogram was not documented, it remains ambiguous and speculative whether the radiologist and the responsible surgeon who typically leads the trauma unit team unequivocally communicated the pathological findings and discussed the possibility of an acute dissection. The atypical symptoms might have made the patient appear not to be seriously ill, which therefore made the diagnosis of an AAD unlikely. A high level of suspicion for AAD and its variable presentations is crucial to early diagnosis and the prevention of high mortality and morbidity.

\section{CONFLICT OF INTEREST}

Nothing to declare.

\section{REFERENCES}

1. Pate JW, Richardson RL, Eastridge CE. Acute aortic dissections. Am Surg. 1976;42:395-404. 
2. Wheat MW. Treatment of dissecting aneurysms of the aorta: current status. Prog Cardiovasc Dis. 1973;16:87-101.

3. Hagan PG, Nienaber CA, Isselbacher EM, et al. The International Registry of Acute Aortic Dissection (IRAD): new insights into an old disease. JAMA. 2000;283:897-903.

4. Coselli J, LeMaire S. Thoracic aortic aneurysms and aortic dissections. In: Brunicardi FC, ed. Schwartz's principles of surgery: McGraw-Hill/New York; 2004.

5. Jamieson WR, Munro AI, Miyagishima RT, Allen P, Tyers GF, Gerein AN. Aortic dissection: early diagnosis and surgical management are the keys to survival. Can J Surg. 1982;25:145149.

6. Spittell PC, Spittell JA, Joyce JW, et al. Clinical features and differential diagnosis of aortic dissection: experience with 236 cases (1980 through 1990). Mayo Clin Proc. 1993;68:642-651.

7. Lindsay J, Hurst JW. Clinical features and prognosis in dissecting aneurysm of the aorta. A re-appraisal. Circulation. 1967;35:880-888.

8. Slater E. Aortic dissection: presentation and diagnosis. In: Doroghazi EM, Slater EE, eds. New York: McGraw-Hill; 1983.

9. Gore I, Hirst A. The etiology and pathology of aortic dissection. In: Doroghazi EM, Slater E, eds. New York: McGraw-Hill; 1983.

10. Pape LA, Awais M, Woznicki EM, et al. Presentation, Diagnosis, and Outcomes of Acute Aortic Dissection: 17-Year Trends From the International Registry of Acute Aortic Dissection. J Am Coll Cardiol. 2015;66:350-358. doi: 10.1016/j.jacc.2015.05.029.

11. Earnest Ft, Muhm JR, Sheedy PF. 2nd. Roentgenographic findings in thoracic aortic dissection. Mayo Clin Proc. 1979;54:43-50.

12. Siegelman SS, Sprayregen S, Strasberg Z, Attai LA, Robinson G. Aortic dissection and the left renal artery. Radiology. 1970;95:73-78. 